\title{
Patient dose reduction during voiding cystourethrography
}

\begin{abstract}
Voiding cystourethrography (VCUG) is a commonly performed examination in a pediatric uroradiology practice. This article contains suggestions on how the radiation dose to a child from VCUG can be made "as low as reasonably achievable" (ALARA). The pediatric radiologist should consider the appropriateness of the clinical indication before performing VCUG and utilize radiation exposure techniques and parameters during VCUG to reduce radiation exposure to a child. The medical physicist and fluoroscope manufacturer can also work together to optimize a pulsed-fluoroscopy unit and further reduce the radiation exposure. Laboratory and clinical research is necessary to investigate methods that reduce radiation exposures during VCUG, and current research is presented here.
\end{abstract}

Keywords Cystourethrography $\cdot$ Radiation dose

\section{Introduction}

Fluoroscopy is commonly performed in pediatric radiology. In particular, voiding cystourethrography (VCUG) is a frequent fluoroscopic examination that is usually performed in a child with a febrile urinary tract infection or prenatal hydronephrosis to detect and characterize vesicoureteral reflux [1]. The ionizing radiation associated with VCUG makes ALARA an important guiding principle for pediatric radiologists with the goal of minimizing the potential longitudinal effects of ionizing radiation on the rapidly growing and radiosensitive tissues of children

V. L. Ward ( $\bowtie)$

Department of Radiology, Children's Hospital Boston and Harvard Medical School,

300 Longwood Ave.,

Boston, MA 02115, USA

e-mail: valerie.ward@ childrens.harvard.edu

Tel.: +1-617-3555462

Fax: +1-617-7300573
[2-6]. A pediatric fluoroscopist should consider many options for decreasing the radiation exposure delivered to a child by VCUG, including (1) only performing the examination for the correct clinical indication and thereby eliminating the potential for radiation exposure from an unnecessary imaging examination; (2) refining the pediatric radiologist's technique in conducting the examination; and (3) making equipment modifications to the fluoroscope to optimize radiation exposure reduction techniques. Ongoing research that assesses imaging technologies that will further reduce radiation exposures of pediatric patients is also critical to the ALARA principle in the routine clinical performance of VCUG.

\section{Clinical indications for the performance of VCUG}

Prior to beginning VCUG, the radiologist should obtain a thorough clinical history and confirm that the referring physician's reason for performing the examination is a correct clinical indication such as a febrile urinary tract infection or prenatal hydronephrosis [1]. Of note, there are instances when the diagnosis of vesicoureteral reflux is best made by radionuclide cystography (RNC) rather than VCUG [1]. The clinical indications for RNC include family screening, follow-up of known vesicoureteral reflux, or follow-up after surgery (for example ureteral reimplantation surgery) [1]. VCUG delivers a much higher effective radiation dose to a child than $\mathrm{RNC}$ (unpublished data; [7-9]). RNC provides continuous monitoring of bladder filling and voiding [8]. However, RNC provides less anatomic conspicuity than VCUG, such that RNC precludes the ability to evaluate the urethra and bladder (for example RNC does not allow the determination of the presence of a para-ureteral diverticulum, which could change patient management) $[1,8,10]$. Therefore, it is important to make certain that the child actually needs an imaging examination based on the clinical history, and if so, then to choose between VCUG and $\mathrm{RNC}$ based on the appropriate clinical indication. 


\section{Operator issues: the radiologist's VCUG technique to reduce} radiation exposure

Methods to reduce radiation exposure while performing VCUG in a child include important technique choices by the radiologist as he/she operates the fluoroscope. For example, a radiologist might choose to perform multiple cycles of bladder filling and emptying (i.e., cyclic VCUG) to increase the diagnostic yield of detecting vesicoureteral reflux $[11,12]$. However, the radiologist must remain aware that each cycle incrementally increases the radiation exposure of a child, so cyclic VCUG should only be performed after the pretest probability of vesicoureteral reflux has been considered and in selected patient populations $[11,12]$.

Similarly, the radiologist can control the overall amount of real-time fluoroscopy and number of actual recorded images that comprise the examination and hence the resultant total radiation exposure $[10,13,14]$. Investigators have tailored VCUG protocols to exclude preliminary images, utilize the fluoroscopy capture mode and optimize digital fluoroscopy video techniques [10,13-17] all in an attempt to reduce radiation exposures.

The radiologist can also reduce radiation exposure by choosing to use pulsed fluoroscopy rather than the conventional, continuous fluoroscopy [18]. Unlike continuous fluoroscopy, pulsed fluoroscopy has multiple available pulse rates (number of radiation beam pulses per second) and pulse widths (duration of each pulse) [19, 20]. If the radiologist performing VCUG selects a lower pulse rate, then the radiation exposure to the patient is reduced. If a narrower pulse width is used for small children who sometimes move during imaging, then image quality is improved. Pulsed fluoroscopy has recently been shown to decrease radiation exposure in an adult study and in a pediatric phantom study $[18,19,21,22]$.

Last, other VCUG radiation exposure reduction techniques include increasing the source-to-skin distance (i.e., maximize the distance between the child and the X-ray source), and removing the antiscatter grid between the patient (source of scattered radiation) and the detector [23].

\section{Modification or optimization of the fluoroscope}

The manufacturer and medical physicist can work together to optimize a fluoroscope's design to achieve ALARA levels [24, 25]. A survey of pediatric hospitals in 2000 showed that those with a pulsed fluoroscopy unit had the lowest radiation exposures, especially those fluoroscopes that were optimized for pediatric imaging [24]. Our group recently compared radiation exposures between pulsed and continuous fluoroscopy in a pediatric-size porcine model of vesicoureteral reflux during the performance of VCUG with a pulsed fluoroscope that was modified by the manufacturer for children [25]. These design features included spectral beam filtration (adding filters in the path of the X-ray beam), proper selection of the tube current and high voltage by the automatic brightness control system as a function of the child's size, reductions in the selectable

Table 1 Comparison of radiation exposure and fluoroscopy time

\begin{tabular}{llrr}
\hline Variable & Continuous fluoroscopy & Grid-controlled variable-rate pulsed fluoroscopy & $F$ test \\
\hline Total radiation exposure & & & $P$ value \\
(mGy) & & & 62.87 \\
Group 1 & $0.60 \pm 0.05$ & $0.13 \pm 0.05$ & 342.97 \\
Group 2 & $1.71 \pm 0.10$ & $0.26 \pm 0.04$ & $<0.001^{*}$ \\
Group 3 & $3.92 \pm 0.20$ & $0.52 \pm 0.07$ & 357.85 \\
Fluoroscopic radiation & & & $<0.001^{*}$ \\
exposure (mGy) & & & 22.99 \\
Group 1 & $0.32 \pm 0.04$ & $0.07 \pm 0.03$ & $0.17^{*}$ \\
Group 2 & $1.05 \pm 0.13$ & $0.16 \pm 0.04$ & $0.02^{*}$ \\
Group 3 & $2.31 \pm 0.47$ & $0.26 \pm 0.03$ & $<0.01^{*}$ \\
Recorded image radiation & & & 72.03 \\
exposure (mGy) & & & 105.91 \\
Group 1 & $0.28 \pm 0.02$ & $0.07 \pm 0.03$ & 121.02 \\
Group 2 & $0.77 \pm 0.06$ & $0.10 \pm 0.01$ & $0.002^{*}$ \\
Group 3 & $1.62 \pm 0.18$ & $0.26 \pm 0.03$ & $0.002^{*}$ \\
Fluoroscopy time (min) & & & $0.003^{*}$ \\
Group 1 & $0.75 \pm 0.05$ & $1.02 \pm 0.15$ & 72.03 \\
Group 2 & $1.18 \pm 0.14$ & $1.34 \pm 0.21$ & 0.21 \\
Group 3 & $1.35 \pm 0.32$ & $1.45 \pm 0.23$ & 0.22 \\
\hline Da are & & 2.50 \\
\end{tabular}

Data are means \pm standard error, based on within-subjects analysis of variance. The means and standard errors are based on two measurements for GCPFL and two for continuous fluoroscopy in one pig by two experienced pediatric radiologists *Statistically significant

Reproduced with the permission of the Radiological Society of North America, CRSNA, 2006; Ward VL, Barnewolt CE, Strauss KJ, et al (2006) Radiation exposure reduction during voiding cystourethrography in a pediatric porcine model of vesicoureteral reflux. Radiology 238:96-106 
Fig. 1 Comparisons of (a) total radiation exposure, (b) fluoroscopic radiation exposure,

(c) recorded image radiation exposure, and (d) fluoroscopy time between the continuous fluoroscopy and GCPFL units for all three groups. Group 1 corresponds to girths in the range $8-10 \mathrm{~cm}$ (human newborn to 6-month-old infant), group 2 to girths in the range $12-13 \mathrm{~cm}$ (2- to 3-year-old child), and group 3 to girths in the range 15-17 cm (10-year-old child). The radiation exposures are expressed as kerma. Reproduced with the permission of the Radiological Society of North America, CRSNA, 2006; Ward VL, Barnewolt CE, Strauss KJ, et al (2006) Radiation exposure reduction during voiding cystourethrography in a pediatric porcine model of vesicoureteral reflux. Radiology 238:96-106

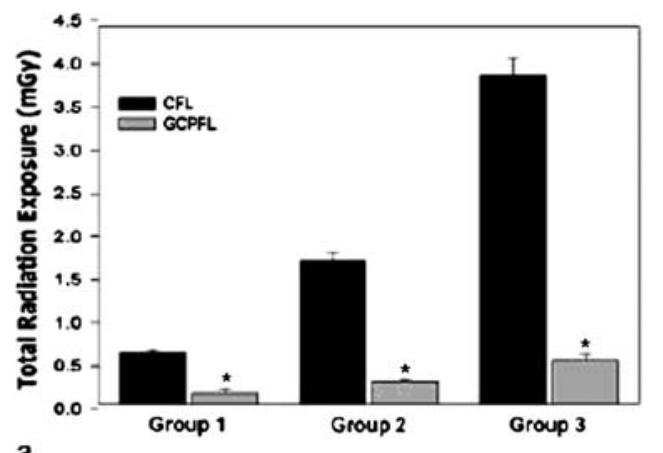

a

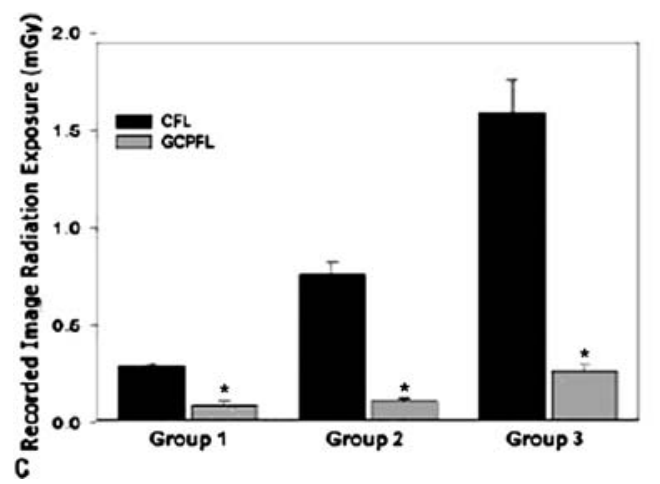

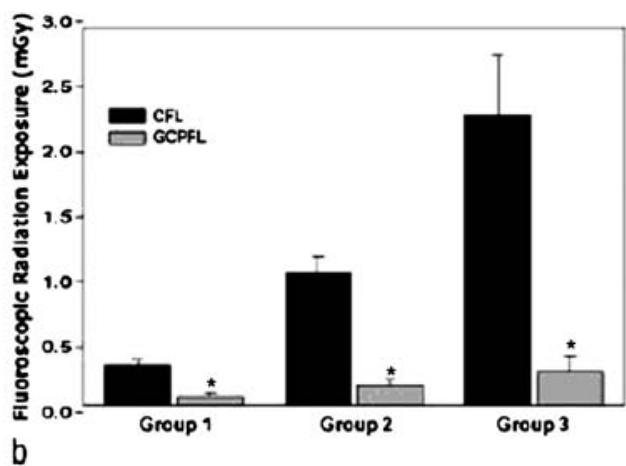

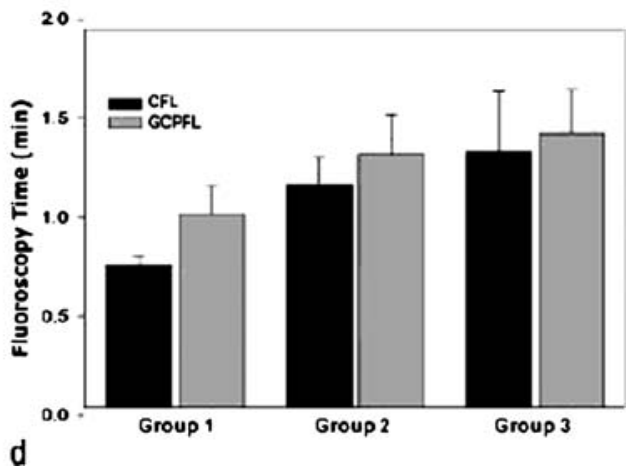

pulse rates to $7.5,3.75$ and 1.88 pulses/s, and reductions in the available selectable pulse widths to $5 \mathrm{~ms}$ and $10 \mathrm{~ms}$ [25]. These design modifications enhanced our ability to achieve statistically significant reduction in total radiation exposures while performing VCUG and maintaining diagnostic image quality.
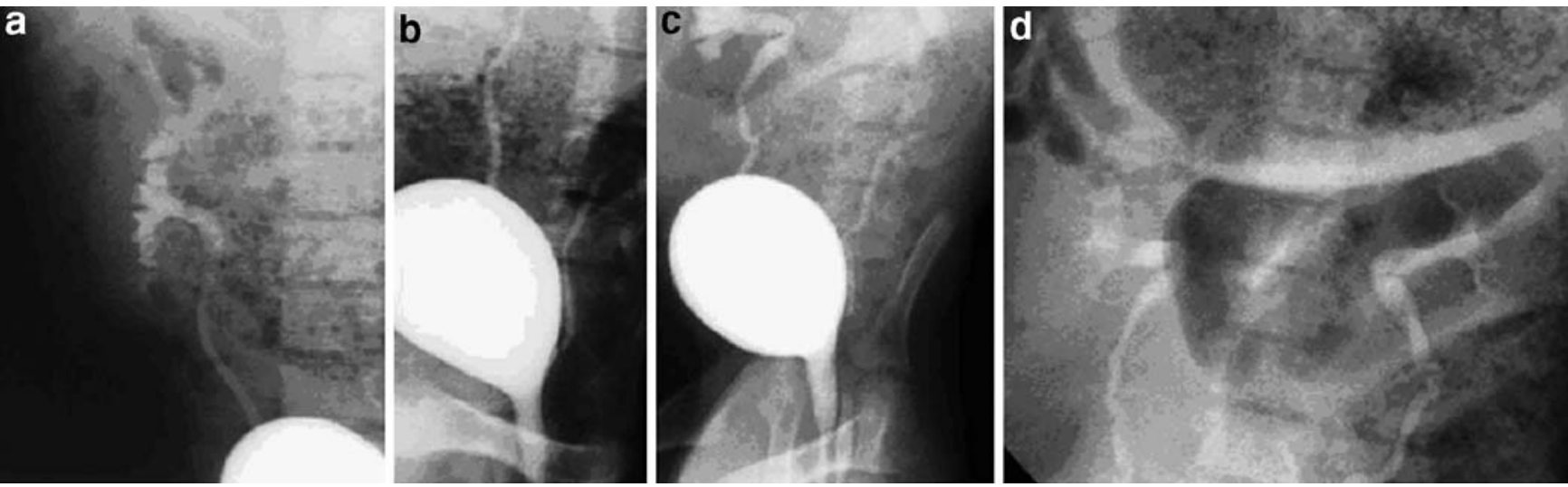

Fig. 2 Recorded VCUG images in group 1 (abdominal girth 8$10 \mathrm{~cm}$ ) that were assigned the best conspicuity score of 1 (i.e., renal calyces, uterovesical junctions, urinary bladder contour, urethra, and bone trabecular pattern all seen with an acceptable low level of noise). Contrast material was infused intravenously to constantly opacify renal collecting systems, ureters, and bladder to simulate vesicoureteral reflux, and the pigs are voiding. a, b Continuous fluoroscopy images obtained with total radiation exposure of $0.73 \mathrm{mGy}$. a Anteroposterior collimated-down view of right kidney demonstrates vesicoureteral reflux. b Left oblique full-bladder view

\section{Current research in pulsed fluoroscopy}

The animal model investigation of VCUG with pulsed fluoroscopy that was performed by our group was as follows. We compared an optimized, grid-controlled variable-rate pulsed fluoroscopy (GCPFL) unit to a continuous fluoroscopy unit in a pediatric porcine model of vesicoureteral reflux [25]. The pigs underwent VCUG at three different abdominal girth ranges that corresponded to the girth of a newborn to 6-month-old human infant (group 1), of the ureterovesical junction. c, d GCPFL images, in a different pig, obtained with total entrance radiation exposure of only $0.078 \mathrm{mGy}$. c Left oblique full-bladder view of the ureterovesical junction. d Anteroposterior collimated-down view of both kidneys demonstrates vesicoureteral reflux. Reproduced with the permission of the Radiological Society of North America, CRSNA, 2006; Ward VL, Barnewolt CE, Strauss KJ, et al (2006) Radiation exposure reduction during voiding cystourethrography in a pediatric porcine model of vesicoureteral reflux. Radiology 238:96-106 

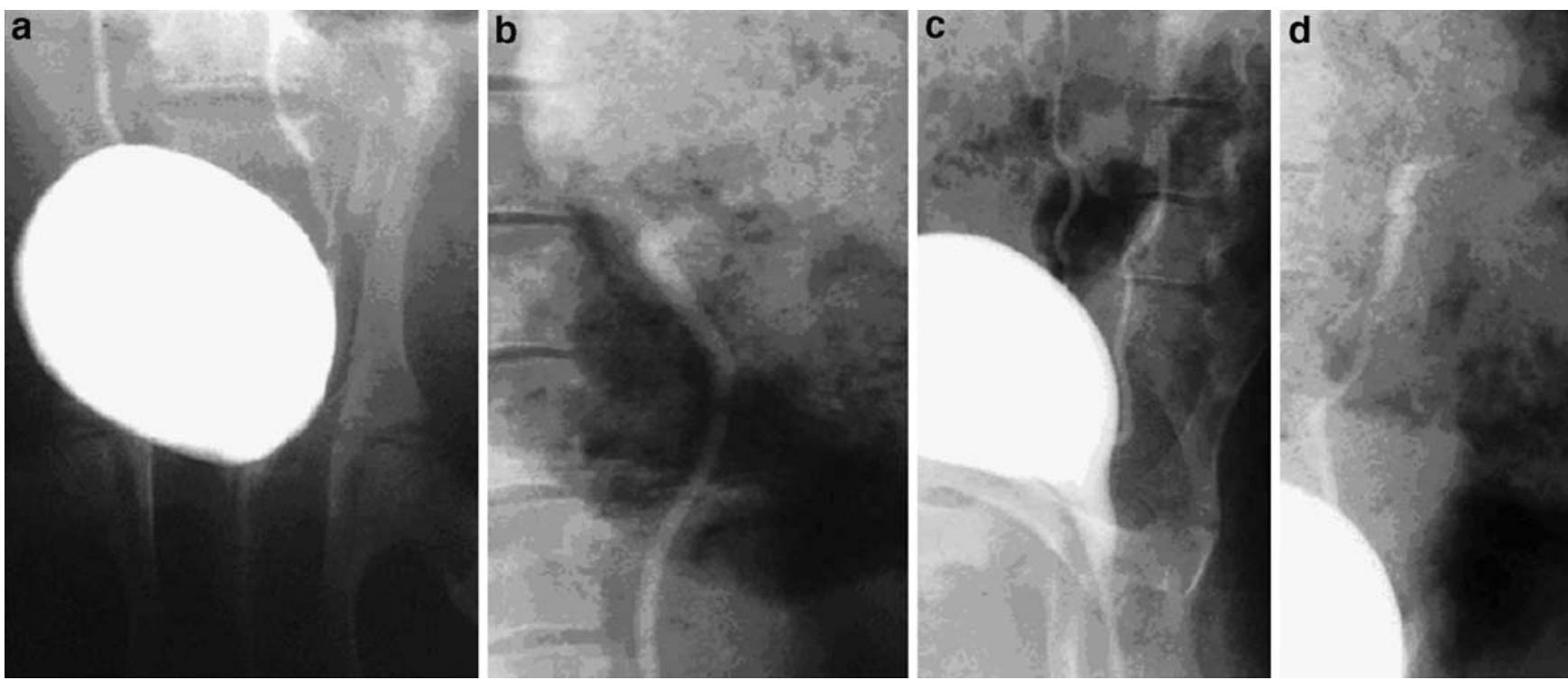

Fig. 3 Recorded VCUG images in group 2 (abdominal girth 12$13 \mathrm{~cm}$ ) that were assigned a diagnostic quality score of 1 (i.e., the highest diagnostic quality). Contrast material is in the renal collecting systems, ureters, bladder, and urethra. a, b Continuous fluoroscopy images obtained with total radiation exposure of 1.6 mGy. c, d GCPFL images in the same pig as in a and $\mathbf{b}$, with total entrance radiation exposure of only $0.33 \mathrm{mGy}$. a, c Left oblique full-

a young child approximately 2 to 3 years of age (group 2), and an older child approximately 10 years of age (group 3). An electronic online patient exposure monitoring device was used to accurately calculate the exposure at the entrance skin plane of the animal [26, 27]. Table 1 and Fig. 1 summarize our results for total radiation exposure, fluoroscopic radiation exposure, recorded VCUG image exposure and fluoroscopy time for all three groups [25]. The optimized GCPFL unit delivered radiation exposures to a pig that ranged from 4.6 to 7.5 times lower than with a continuous fluoroscopy unit. The fluoroscopy times for VCUG between the fluoroscopy units were not signifi-

Table 2 Comparison of anatomic conspicuity scores

\begin{tabular}{lrcl}
\hline $\begin{array}{l}\text { Radiologist and Continuous } \\
\text { girth group }\end{array}$ & $\begin{array}{l}\text { Grid-controlled variable- } \\
\text { fluoroscopy }\end{array}$ & $\begin{array}{l}P \\
\text { rate pulsed fluoroscopy }\end{array}$ \\
\hline Radiologist A & & & \\
Group 1 & $1.5(1-2)$ & $1(1-1)$ & $0.04^{*}$ \\
Group 2 & $1(1-4)$ & $1(1-2)$ & 0.18 \\
Group 3 & $2(1-5)$ & $1(1-3)$ & 0.32 \\
Radiologist B & & & \\
Group 1 & $2(1-3)$ & $1.5(1-2)$ & 0.25 \\
Group 2 & $1(1-3)$ & $1(1-2)$ & 0.56 \\
Group 3 & $1(1-3)$ & $1(1-1)$ & 0.32 \\
\hline
\end{tabular}

Data are medians, and data in parentheses are ranges. A score of 1 indicates the best conspicuity

*Statistically significant

Reproduced with the permission of the Radiological Society of North America,CRSNA,2006; Ward VL, Barnewolt CE, Strauss $\mathrm{KJ}$, et al (2006) Radiation exposure reduction during voiding cystourethrography in a pediatric porcine model of vesicoureteral reflux. Radiology 238:96-106 bladder views of the ureterovesical junction. $\mathbf{b}, \mathbf{d}$ Collimated-down views of the left kidney demonstrating vesicoureteral reflux. Reproduced with the permission of the Radiological Society of North America, CRSNA, 2006; Ward VL, Barnewolt CE, Strauss $\mathrm{KJ}$, et al (2006) Radiation exposure reduction during voiding cystourethrography in a pediatric porcine model of vesicoureteral reflux.

cantly different. Figures 2 and 3 are examples of actual recorded VCUG images demonstrating that anatomic conspicuity and diagnostic image quality were maintained. Tables 2 and 3 underscore the anatomic conspicuity and diagnostic image quality scores for the 48 VCUGs assigned by two experienced pediatric radiologists [25].

Subsequently, our group translated these findings to our routine clinical pediatric uroradiology practice. The optimized GCPFL unit used in the animal model investigation was compared with the same conventional, continuous fluoroscopy unit in a human study. We found that the GCPFL unit could significantly reduce the

Table 3 Comparison of diagnostic quality scores

\begin{tabular}{lrlr}
$\begin{array}{l}\text { Radiologist and } \\
\text { girth group }\end{array}$ & $\begin{array}{l}\text { Continuous } \\
\text { fluoroscopy }\end{array}$ & $\begin{array}{l}\text { Grid-controlled variable- } \\
\text { rate pulsed fluoroscopy }\end{array}$ & $\begin{array}{l}P \\
\text { value }^{\mathrm{a}}\end{array}$ \\
\hline $\begin{array}{l}\text { Radiologist A } \\
\text { Group 1 }\end{array}$ & $2(1-3)$ & $2(1-3)$ & $>0.99$ \\
Group 2 & $2.5(2-3)$ & $2(1-3)$ & 0.56 \\
Group 3 & $2(1-3)$ & $2(2-3)$ & 0.65 \\
Radiologist B & & & \\
Group 1 & $2(1-3)$ & $2(1-2)$ & 0.26 \\
Group 2 & $2(1-3)$ & $2(1-2)$ & 0.98 \\
Group 3 & $1(1-3)$ & $1(1-1)$ & 0.32 \\
\hline
\end{tabular}

Data are medians, and data in parentheses are ranges. A score of 1 indicates the best diagnostic quality

${ }^{a}$ Wilcoxon signed ranks test

Reproduced with the permission of the Radiological Society of North America, CRSNA, 2006; Ward VL, Barnewolt CE, Strauss $\mathrm{KJ}$, et al (2006) Radiation exposure reduction during voiding cystourethrography in a pediatric porcine model of vesicoureteral reflux. Radiology 238:96-106 Radiology 238:96-106 
radiation exposures of children with common clinical indications for VCUG. The statistically significant radiation exposure reductions with the GCPFL unit were achieved during both fluoroscopy and the actual recording of VCUG images (unpublished data). Moreover, at these lower radiation exposures, the GCPFL unit still provided diagnostic quality images. Hence, an optimized GCPFL unit has the potential to provide an optimal balance between reducing radiation exposure of a child and maintaining diagnostic image quality (unpublished data).

\section{Conclusion}

In order to obtain ALARA levels in the performance of VCUG in children, the pediatric radiologist should consider the appropriateness of the clinical indication for the examination, the gamut of available operational techniques available, and the potential equipment modifications necessary to optimize the fluoroscope. Current investigations show that VCUG performed with an optimized pulsed fluoroscope can achieve ALARA levels and maintain diagnostic image quality.

Acknowledgement The author wishes to thank Keith J. Strauss, M. Sc., F.A.A.P.M., for all of his insightful contributions to this article.

\section{References}

1. Lebowitz RL (1992) The detection and characterization of vesicoureteral reflux in the child. J Urol 148:1640-1642

2. Ron E (2002) Ionizing radiation and cancer risk: evidence from epidemiology. Pediatr Radiol 32:232-237

3. Ron E (2002) Let's not relive the past: a review of cancer risk after diagnostic or therapeutic irradiation. Pediatr Radiol 32:739-744

4. Hall EJ (2002) Lessons we have learned from our children: cancer risks from diagnostic radiology. Pediatr Radiol 32: 700-706

5. Beir V (1990) Health effects of exposure to low levels of ionizing radiation. Committee on the Biological Effects of Ionizing Radiations. National Academy Press, Washington DC

6. Huda W (2004) Assessment of the problem: pediatric doses in screen-film and digital radiography. Pediatr Radiol 34 [Suppl 3]:S173-S182

7. Mandell GA, Eggli DF, Gilday DL, et al (1997) Procedure guideline for radionuclide cystography in children. J Nucl Med 38:1650-1654

8. Treves ST, Gelfand M, Willi UV (1995) Vesicouretic reflux and radionuclide cystography. In: Treves ST (ed) Pediatric nuclear medicine, 2nd edn. Springer, Berlin Heidelberg New York, pp 411-429
9. Conway JJ, King LR, Belman AB, et al (1972) Detection of vesicoureteral reflux with radionuclide cystography. AJR 115:720-727

10. Diamond DA, Kleinman PK, Spevak M, et al (1996) The tailored low dose fluoroscopic voiding cystogram for familial reflux screening. J Urol 155:681-682

11. Paltiel HJ, Rupich RC, Kiruluta HG (1992) Enhanced detection of vesicoureteral reflux in infants and children with use of cyclic voiding cystourethrography. Radiology 184:753-755

12. Gelfand MJ, Koch BL, Elgazzar AH, et al (1999) Cyclic cystography: diagnostic yield in selected pediatric populations. Radiology 213:118-120

13. Lebovic S, Lebowitz, R (1980) Reducing patient dose in voiding cystourethrography. Urol Radiol 2:103-107

14. Kleinman PK, Diamond DA, Karellas A, et al (1994) Tailored low-dose fluoroscopic voiding cystourethrography for the reevaluation of vesicoureteral reflux in girls. AJR 162: $1151-1154$

15. O'Connor SJ, Wirt MD, Ruess L, et al (2004) Image capture vs. spot radiographic exposures for the detection and grading of vesicoureteral reflux in children with digital fluoroscopy. Pediatr Radiol 34:S50

16. Cleveland RH, Constantinou C, Blickman JG, et al (1992) Voiding cystourethrography in children: value of digital fluoroscopy in reducing radiation dose. AJR 158:137-142

17. Persliden J, Helmrot E, Hjort P, et al (2004) Dose and image quality in the comparison of analogue and digital techniques in paediatric urology examinations. Eur Radiol 14:638-644

18. Hernandez RJ, Goodsitt MM (1996) Reduction of radiation dose in pediatric patients using pulsed fluoroscopy. AJR 167:1247-1253

19. Boland GWL, Murphy B, Arellano R, et al (2000) Dose reduction in gastrointestinal and genitourinary fluoroscopy: use of grid-controlled pulsed fluoroscopy. AJR 175:1453-1457

20. Hahn H, Farber D, Allmendinger H, et al (1997) Gridcontrolled fluoroscopy in paediatric radiology. Medicamundi 41:12-17

21. Brown PH, Thomas RD, Silberberg PJ, et al (2000) Optimization of a fluoroscope to reduce radiation exposure in pediatric imaging. Pediatr Radiol 30:229-235

22. Lederman HM, Khademian ZP, Felice M, et al (2002) Dose reduction fluoroscopy in pediatrics. Pediatr Radiol 32:844-848

23. Bushberg JT, Seibert JA, Leidholdt EM Jr, et al (1994) The essential physics of medical imaging. Williams and Wilkins, Baltimore, pp 159-168 and 600

24. Brown PH, Silberberg PJ, Thomas RD, et al (2000) A multihospital survey of radiation exposure and image quality in pediatric fluoroscopy. Pediatr Radiol 30:236-242

25. Ward VL, Barnewolt CE, Strauss KJ, et al (2006) Radiation exposure reduction during voiding cystourethrography in a pediatric porcine model of vesicoureteral reflux. Radiology 238:96-106

26. Strauss KJ (1995) Clinical radiation dose monitoring. In: Categorical course in physics, physical and technical aspects of angiography and interventional radiology. Radiological Society of North America, Oak Brook, Ill., pp 171-187

27. Gkanatsios NA, Huda W, Peters KR, et al (1997) Evaluation of an on-line patient exposure meter in neuroradiology. Radiology 203:837-842 